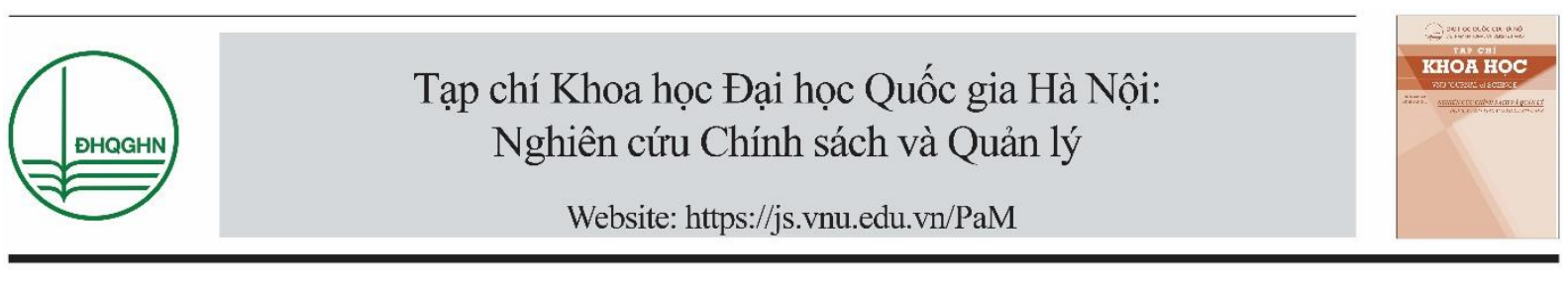

\title{
Chính quyền địa phương và thực hiện chính sách ứng phó biến đổi khí hậu tại trung quốc: Bài học kinh nghiệm cho Việt Nam
}

\author{
Ngô Hoài Sơn ${ }^{1}$, Nguyễn Văn Hoà2,** \\ ${ }^{1}$ Trường Đại học Quốc tế, Đại học Quốc gia Tp. Hồ Chí Minh, Khu phố 6, \\ P.Linh Trung, Q. Thủ Đíc, TP.HCM, Việt Nam \\ ${ }^{2}$ Học viện Khoa học Công nghệ và Đổi mới sáng tạo, Bộ Khoa học và Công nghệ, \\ 38 Ngô Quyền, Hoàn Kiếm, Hà Nọi, Việt Nam \\ Nhận ngày 13 tháng 12 năm 2018 \\ Chỉnh sửa ngày 21tháng 12 năm 2018; Chấp nhận đăng ngày 23 tháng 12 năm 2018
}

\begin{abstract}
Tóm tắt: Trên cơ sở nghiên cứu một số tài liệu thứ cấp liên quan đến thực hiện chính sách biến đổi khí hậu ở chính quyền địa phương của Trung Quốc, bài viết tiến hành tổng thuật lại cách thức mà Trung Quốc làm cho chính quyền địa phương trở thành một chủ thể không thể thiếu trong quá trình thực hiện chính sách này. Từ đó phân tích và rút ra những bài học kinh nghiệm cho Việt Nam. Bài viết đúc kết được bốn bài học. Thứ nhất là cần kết hợp cách tiếp cận tù duới lên và tùt trên xuống trong quy trình chính sách ứng phó biến đổi khí hậu. Thứ hai, chính quyền địa phương phải thật sự chuyển hoá, lồng ghép các mục tiêu về môi trường vào kế hoạch phát triển kinh tế-xã hội của địa phương mình. Thứ $b a$, xem trọng vai trò và tạo điều kiện cho tố chức xã hội dân sự tham gia tích cực vào việc tương tác với chính quyền các cấp xuyên suốt quá trình chính sách ứng phó biến đổi khí hậu. Thứ tux, yếu tố tạo nên sự thành công trong việc thực hiện chính sách ứng phó biến đổi khí hậu là ý thức và quan niệm của địa phương và trung ương về môi trường.
\end{abstract}

Tù khoá: Chính quyền địa phương, biến đổi khí hậu, Trung Quốc.

\section{Mở đầu}

Chiếm 20\% dân số thế giới, Trung Quốc đang đối mặt với bài toán nan giải về mối quan hệ giữa tăng trưởng kinh tế và giảm thiểu ô nhiễm môi trường. Dưới áp lực của thế giới, tổ chức xã hội dân sự (NGO) và tình trạng môi trường ô nhiễm trầm trọng, Trung Quốc đang

\footnotetext{
*Tác giả liên hệ. ĐT.: 84-969211218.

Email: htvm2018@gmail.com

https://doi.org/10.25073/2588-1116/vnupam.4164
}

có nhiều nỗ lực cải thiện môi trường và giải quyết vấn đề năng lượng bền vững. Trong nỗ lực này, sự năng động và tham gia tích cực của chính quyền địa phương ở Trung Quốc có vai trò quan trọng. Thế nhưng Trung Quốc đang đối diện với nhiều rào cản để có thể phát huy nỗ lực của chính quyền địa phương. Nhiều hành động, hỗ trợ và quy định đã được đưa ra cho địa phương; một số phát huy hiệu quả, một số bị thất bại. Nhưng dù như thế nào, chúng vẫn là những bài học có giá trị cho Việt Nam trong 
việc phát huy vai trò của chính quyền địa phương trong chính sách ứng phó biến đổi khí hậu.

Có nhiều lý do lý để tác giả chọn nghiên cứu bài học về môi trường từ Trung Quốc. Đó là sự gần gũi về mặt địa lý, sự tương đồng về tư duy phát triển, sự ảnh hưởng về chính sách phát triển và sức ảnh hưởng cùng với vai trò chủ chốt của Trung Quốc trong các các vấn đề về môi trường ở khu vực và thế giới. Mặc dù chính sách về môi trường của quốc gia này chưa thật sự hiệu quả như mong đợi, nhưng ngay cả khi thất bại thì vẫn có nhiều bài học có giá trị cho Việt Nam để không phải "đạp lên vết xe đổ" của người hàng xóm.

\section{Giới thiệu về chính sách ứng phó biến đổi khí hậu tại Trung Quốc}

Năm 1970, Trung Quốc tham gia đối thoại toàn cầu về môi trường ở Hội nghị môi trường của Liên Hiệp quốc tổ chức tại Stockholm. Tại Hội nghị này, Trung Quốc thể hiện quan điểm mang đầy màu sắc tự vệ khi cho rằng vấn đề nằm ở các nước phát triển phương Tây [1], chứ không nằm ở một quốc gia đang phát triển như Trung Quốc. Ngay sau đó đến năm 1973, quan điểm của Trung Quốc về môi trường bắt đầu thay đổi. Nhận thấy vấn đề môi trường của mình diễn biến ngày càng trầm trọng, Trung Quốc chủ động tổ chức hội thảo quốc gia về môi trường. Những năm tiếp theo, cụ thể là vào những năm đầu 1980 , vấn đề bảo vệ môi trường trở thành một trong những "phát ngôn chính sách" cơ bản ở Trung Quốc [1].

Từ đó, chính sách ứng phó biến đổi khí hậu ở Trung Quốc được hình thành và ngày càng hoàn thiện. Từ khi hình thành tới nay, chính sách ứng phó biến đổi khí hậu của Trung Quốc có thể được chia thành 03 giai đoạn: 19901992, 1992-1997, và 1997 đến nay.

Giai đoạn 1 , vấn đề biến đổi khí hậu trở thành chương trình nghị sự ở Trung Quốc (những năm 1980-1992). Vào cuối những năm 1982, biến đổi khí hậu ở Trung Quốc trở thành vấn đề quốc tế quan trọng thu hút sự chú ý của công chúng, thông tin đại chúng, nhà khoa học và các quốc gia trên toàn thế giới [1]. Ở giai đoạn này, Trung Quốc thành lập Nhóm Điều phối Biến đổi khí hậu Quốc gia nằm trong $\mathrm{Cơ}$ quan Bảo vệ môi trường [2].

Chính sách ứng phó biến đổi khí hậu trong giai đoạn này hướng đến một số trọng tâm như: (1) đề cao những nghiên cứu khoa học về sự bất định của biến đổi khí hậu; (2) bảo vệ lãnh thổ quốc gia; (3) trách nhiệm của một quốc gia phát triển; (4) chuyển giao các quỹ và công nghệ mới và công nghệ bổ sung tới các nước đang phát triển [2].

Giai đoạn 2 từ năm 1992 đến 1997. Vào năm 1992, Trung Quốc đăng ký tham gia UNFCCC và được phê chuẩn vào năm 1994. Trong giai đoạn này có thêm sáu hội thảo $\mathrm{INC}$, và Trung Quốc nhấn mạnh đến việc buộc phải triển khai thực hiện các cam kêt ở Mục lục 1 của COP's [2]. Vào năm 1998, Trung Quốc đăng kí tham gia Hiệp định Kyoto và được phê chuẩn vào năm 2002.

Trong giai đoạn này, Trung Quốc có nhiều nỗ lực nhưng không hiệu quả, nhất là trong khâu thực hiện mặc dù ở giai đoạn này, Trung Quốc và các quốc gia đang phát triển có thái độ tích cực hơn đối với vấn đề biến đổi khí hậu. Trung Quốc cũng bắt đầu lờ mờ nhận thấy rằng cần phải có những hành động phối hợp quốc tế trong việc thực hiện giải quyết vấn đề môi trường chứ không chỉ đơn giản là tập trung vào những hành động mang tính chất cục bộ ở mỗi quốc gia [3].

Giai đoạn 3: hậu Kyoto-Trung Quốc (từ năm 1997 đến nay). Ở giai đoạn này, Trung Quốc tiếp tục quy trách nhiệm về ô nhiễm môi trường cho các nước phát triển. Trung Quốc tiếp tục né tránh các cam kết Kyoto ở các nước đang phát triển. Không những vậy, trong suốt hội nghị COP-4 ở Buenos Aires, Trung Quốc cùng với Ấn Độ và các nước đang phát triển khác từ chối những ý tưởng đề cập đến vấn đề cam kết tự nguyện trong ứng phó với biến đổi khí hậu. Đồng thời, Trung Quốc cho rằng các nước phát triển nên thay đồi cách thức sản xuất và tiêu dùng [4]. Thế nhưng, đến COP-5 tại Bonn Trung Quốc bắt đầu thay đổi thái độ và 
định hướng trong thảo luận. Thay vì né tránh và quy trách nhiệm cho các nước phát triển, Trung Quốc bắt đầu thảo luận nguyên tắc và thủ tục để thực hiện dự án CDM trên thực tế.

\section{Chính quyền địa phương và quá trình thực hiện chính sách ứng phó biến đổi khí hậu ở Trung Quốc}

\subsection{Tổ chức bộ máy quản lý nhà nước về môi truờng và biến đổi khi hậu của Trung Quốc}

Hệ thống chính quyền Trung Quốc bao gồm 5 cấp: chính quyền trung ương, chính quyền vùng, chính quyền tỉnh, chính quyền huyện và chính quyền xã [5]. Ở chính quyền Trung ương, cơ quan phụ trách về vấn đề Biến đổi khí hậu là
Bộ Phát triển và Cải cách Quốc gia (National Development and Reform Commission) và Cục Bảo vệ Môi trường Quốc gia (State Environment Protection Agency) [5]. Trong các cơ quan này còn có Hội đồng Điều phối chính sách Biến đổi khí hậu Quốc gia (National Climate Change Policy Coordinating Committee) [5].

Ở địa phương cơ quan chịu trách nhiệm về môi trường là Sở Phát triển và Cải cách, $\mathrm{Chi}$ cục Bảo vệ môi trường. Những cơ quan này chịu trách nhiệm thực hiện chính sách năng lượng, môi trường và biến đổi khí hậu ở địa phương.

Có thể biểu diễn bộ máy ứng phó biến đổi khí hậu của Trung Quốc như sau:

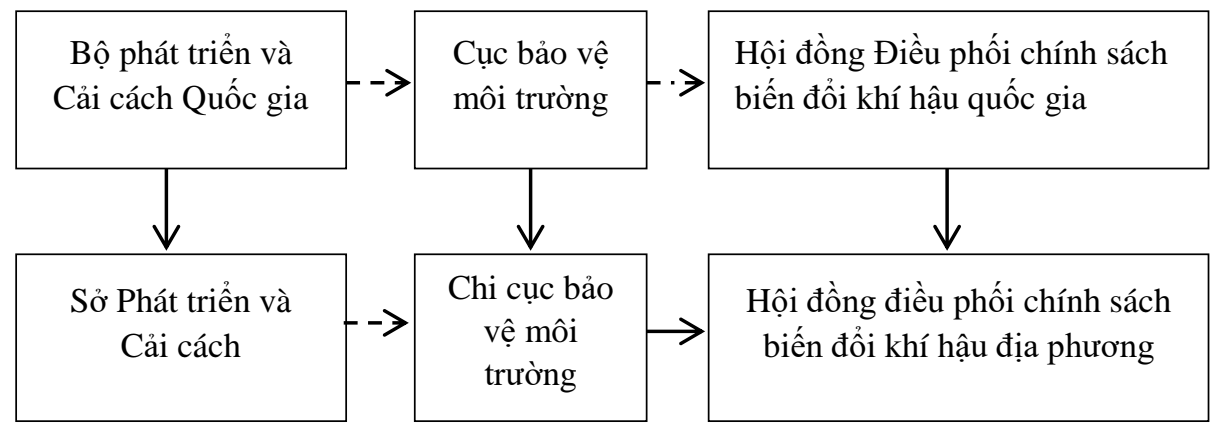

Sơ đồ 1. Bộ máy ứng phó biến đổi khí hậu của Trung Quốc.

(Nguồn: Tác giả tổng hợp)

Theo sơ đồ này, cơ quan nhà nước ở chính quyền trung ương có thẩm quyền ban hành chính sách về môi trường cho cả nước. Cơ quan nhà nước ở cấp dưới chịu trách nhiệm thực hiện chính sách ứng phó biến đổi ở địa phương mình cũng như được phân quyền cho việc ban hành những chương trình hành động về biến đổi khí hậu ở địa phương.

Cơ quan Bảo vệ môi trường bị chi phối bởi 02 mối quan hệ: theo chiều dọc (về chuyên môn) và theo chiều ngang (về địa lý). Chẳng hạn như Cục Bảo vệ môi trường vừa phải chịu trách nhiệm trước Bộ Bảo vệ Môi trường, đồng chịu sự tác động, điều tiết của chính quyền cùng cấp [6]. Do tồn tại hai mối quan hệ mà trong quá trình thực hiện chính sách ứng phó biến đổi khí hậu có xuất hiện hai loại xung đột cơ bản: xung đột giữa cơ quan Bảo vệ Môi trường với cấp trên theo chiều dọc và chính quyền địa phương theo chiều ngang và giữa chính quyền địa phương với chính quyền trung ương [6].

3.2. Xung đột và cách thức giải quyết xung đột trong quá trình thực hiện chính sách biến đổi khi hậu của Trung Quốc

Theo Pressman \& Wildavsky [7], một trong những mặt trái cơ bản của chính quyền có quá nhiều cấp là chính sách được đưa ra từ trung ương có thể bị vô hiệu hoá, “đứng hình" hoặc 
gây khó dễ bởi chính quyền địa phương. Sự "cản trở" này có thể được được cắt nghĩa bởi một số lý do.

Thư nhất là xuất phát từ sự bất đồng về chính sách. Chính quyền địa phương trong nhiều trường hợp không đồng ý với chính sách do trung ương đưa ra vì không phù hợp, không gắn với thực tế của địa phương [8].

Thư hai là do chính quyền địa phương, đối với một số chính sách, không hiểu được đầy đủ; đã làm cho việc thực hiện chính sách bị chậm trễ, hoặc thậm chí là sai lạc [8].

Thứ $b a$ xuất phát từ nguyên nhân nguồn lực. Chính quyền địa phương không đủ nguồn lực về tài chính, con người và kỹ thuật để thực hiện tốt chính sách do trung ương đưa ra [8].

Thí tư là do bản thân chính sách không đảm bảo do được xây dựng thiếu bài bản, khoa học và bỏ qua những điều kiện thực tại của địa phương [8].

Thứ năm là địa phương thiếu ngân sách và không muốn chi nhiều hơn ngân sách vào vấn đề môi trường, thay vào đó, họ tập trung đầu tư để tìm kiếm mục tiêu phát triển kinh tế trong ngắn hạn [9].

Để giải quyết xung đột này, Trung Quốc áp dụng một số biện pháp sau:

Biện pháp thứ nhất, chính quyền trung ương bằng quyền lực của mình sử dụng đồng thời "củ cà rồt" (khuyến khích, khen thường) và "cây gậy" (xử phạt) [9]. Chính quyền trung ương Trung Quốc có chế độ khen thưởng cho những cán bộ công chức ở địa phương tích cực và đóng góp nhiều cho việc thực hiện chính sách môi trường như lồng ghép vào hoạt động đánh giá cán bộ, công chức cuối năm, thăng tiến, tăng lương hoặc thưởng, những lợi ích về vật chất khác như (được đi lại miễn phí, miễn phí các dịch vụ giải trí, tham gia bồi dưỡng và du lịch) và những khoản hỗ trợ khác như trợ cấp nhà ở, chăm sóc sức khoẻ, và cơ hội được học tập cao hơn. Ngược lại, nếu cán bộ, công chức ở địa phương không thực hiện tốt chính sách biến đổi khí hậu sẽ bị những hình phạt như không được thăng tiến, điều động công tác tới vùng sâu, vùng xa, trong một số ít trường hợp, còn bị sa thải. Những người đứng đầu địa phương (cả của Đảng và chính quyền) phải ký hợp đồng trách nhiệm cá nhân cam kết lồng ghép các yêu cầu về năng lượng và khí phát thải hàng năm tại địa phương của mình [9].

Biện pháp thư hai là sử dụng hệ thống kế hoạch dựa trên mục tiêu xanh. Bộ Môi trường yêu cầu 74 thành phố áp dụng tiêu chuẩn $\mathrm{PM} 2.5$ và xuất bản ghi chú hàng ngày về $\mathrm{PM} 2.5$ cho đến cuối năm 2012. Thêm vào đó là tăng cường năng lực quản lý nhà nước về môi trường liên địa phương để bảo vệ trọn vẹn các hệ sinh thái. Bằng cách này, các chính quyền địa phương cùng cam kết chia sẻ nguồn lực bảo vệ môi trường, cùng nhau tìm kiếm và xác định những tác nhân gây ô nhiễm liên địa phương. Tuy hiệu quả của giải pháp này chưa được thể hiện trên thực tế nhưng nó đã làm cho nhận thức của các nhà lãnh đạo ở địa phương về nhu cầu liên kết cùng nhau ngày càng tăng.

Biện pháp thứ $b a$, Trung Quốc cũng đang thí điểm các dự án dựa trên thị trường ở phạm vi nhỏ như: đưa ra hệ thống ba mức giá điện, phát triển các công ty dịch vụ năng lượng, đưa ra nhiều hình thức trả tiền cho dịch vụ môi trường để cải thiện chất lượng nước, không khí, rừng và quản lý đất, và nhiều dự án thí điểm khác ở địa phương nhằm giảm khí phát thải [9].

Biện pháp thư $t u$, tăng nhiều quyền hơn cho chính quyền địa phương trong việc xử lý những công ty thuộc sở hữu của nhà nước trung ương đang hoạt động ở địa phương có gây ô nhiễm.

Biện pháp thứ năm là đẩy mạnh sự tham gia của khu vực tư nhân và công chúng. Trung Quốc mở rộng sự tham gia của các tổ chức NGOs về môi trường vào những buổi họp báo. Đồng thời Trung Quốc cải thiện chất lượng cung cấp thông tin môi trường từ khâu hoạch định đến thực thi chính sách [10]. Tại COP-7 vào năm 2001, Trung Quốc thành lập Hội Đồng Điều hành $\mathrm{CDM}$, làm rõ quy trình dự án và các bên có liên quan, thừa nhận và phê duyệt định mức giảm khí phát thải nhà kính. Sự cởi mở của chính quyền Trung Quốc đã làm tăng số lượng các tổ chức dân sự hoạt động trong lĩnh vực môi trường. Đến năm 2008, ở Trung Quốc có 
tới 5,530 tổ chức xã hội dân sự đăng ký [11]. Thế nhưng ảnh hưởng thực sự của các tổ chức này đến chính sách môi trường của Trung Quốc vẫn còn thấp, đặc biệt là ở khâu xây dựng chính sách môi trường [9].

\section{Một số bài học rút ra}

Từ kết quả phân tích trên, có thể rút ra một số bài học có ý nghĩa cho Việt Nam trong việc huy động chính quyền địa phương vào việc thực hiện chính sách ứng phó biến đồi khí hậu ở Việt Nam như sau:

Thư nhất, cần kết hợp cách tiếp cận tù dưới lên và tì̀ trên xuống trong quy trình chính sách ứng phó biến đổi khí hậu. Quy trình từ dưới lên nhấn mạnh đến sự tham gia một cách rộng rãi của người dân trong quá trình xây dựng và thực hiện chính sách ứng phó biến đồi khí hậu. Sự tham gia của người dân và các bên có liên quan khởi phát từ khâu xác định vấn đề đến khâu lựa chọn giải pháp và thực hiện các giải pháp đó. Sự tham gia của người dân và các chủ thể có liên quan giúp tạo ra cái nhìn đa chiều về cùng một vấn đề, làm cho việc ban hành và thực hiện chính sách phản ánh một cách đầu đủ và sâu sắc hơn các khía cạnh của đối tượng mà chính sách đó điều chỉnh.

Điểm mấu chốt của mô hình từ trên xuống nằm ở vai trò chủ đạo và gần như là duy nhất của chủ thể ban hành. Ở giai đoạn xây dựng chính sách, vai trò khởi xướng thuộc về các cơ quan quản lý nhà nước với rất ít sự tham gia và tương tác của người dân và các chủ thể có liên quan. Ở giai đoạn thực thi chính sách, mô hình thực hiện chính sách ứng phó biến đồi khí hậu từ trên xuống bắt đầu bằng một chương trình hoặc chính sách của nhà nước về biến đổi khí hậu. Trên cơ sở chương trình, chính sách đó, trong quá trình thực thi chính sách, chủ thể thực thi làm theo những việc đã được yêu cầu hoặc đã được thiết kế dưới sự kiểm soát của nhà nước trong suốt quá trình thực thi. Trong mô hình này, các mục tiêu được xác định từ 'trên' thay vì xuất phát từ những đối tượng tham gia chính sách. Mô hình này thường tập trung vào bốn vấn đề chính. Thứ nhất là mức độ theo đuổi chính sách của các đối tượng tham gia thực thi. Thứ hai là mức độ đạt được mục tiêu của chính sách. Thứ ba, xác định những yếu tố cơ bản tác động đến đầu ra cũng như những ai liên quan đển thực thi chính sách (cả trực tiếp và gián tiếp). Thứ tư, cách thức điều chỉnh dựa trên những kinh nghiệm có được.

Trên thực tế, ngay từ giai đoạn thiết kế và hoạch định chính sách cần phải có sự tham gia tích cực của chính quyền địa phương để họ hiểu, nhận thức đầy đủ và thể hiện được mong đợi của họ vào chính sách nhờ đó mà quá trình thực hiện chính sách môi trường được nhận thức đầy đủ và trở nên dễ dàng hơn. Chính vì vậy, cần có sự kết hợp giữa mô hình từ trên xuống và từ dưới lên đề đảm bảo việc thực hiện chính sách ứng phó biến đổi khí hậu ở địa phương được thành công, như bài học kinh nghiệm của Trung Quốc. Cụ thể:

- Tập trung vào những thay đổi về kinh tế xã hội tác động đến mạng lưới hoặc các tiểu mạng lưới thực thi chính sách. Cần xem xét xem cách thức tác động của những thay đổi này đến các nguồn lực và chiến lược hành động của các chủ thể tham gia thực thi chính sách.

- Tập trung xem xét những cố gắng mà các chủ thể tạo ra trong quá trình tham gia thực thi chính sách của nhà nước để đạt được mục tiêu đề ra.

- Tập trung xem xét những nỗ lực mà các chủ thể tham gia trong việc hiểu mức độ quan trọng và những yếu tố tác động đến chính sách, cũng như những tác động của các công cụ khác nhau mà họ có được từ trong quá khứ.

Thư hai, Chính phủ cần có những hành động mạnh mẽ hơn trong việc buộc các chính quyền địa phương phải thật sự chuyển hoá, lồng ghép các mục tiêu về môi trường vào kế hoạch phát triển kinh tế-xã hội của địa phương mình. Tăng cường chất lượng báo cáo về môi trường của địa phương, kiểm soát, rà soát các cam kết về môi trường của chính quyền địa phương, khen thưởng và xử lý nghiêm khắc có thể là những giải pháp cần xem xét để áp dụng cho chính quyền địa phương trong bối cảnh của 
Việt Nam. Theo đó, trong thời gian tới, Việt Nam cần hướng tới một số hành động như sau:

Đưa ra quy định bắt buộc lồng ghép các mục tiêu về môi trường vào phát triển kinh tếxã hội của địa phương. Quy định này có thể được xem là một động lực giúp chính quyền địa phương xem xét lại các mục tiêu về môi trường trong quá trình phát triển kinh tế-xã hội của mình. Không những vậy, cần thiết phải xem đây là căn cứ cho hoạt động phân bổ ngân sách và kiểm soát năng lực thực thi của chính quyền địa phương trong quá trình thực hiện chính sách này.

Không những vậy, để tăng cường chất lượng báo cáo, chính phủ cần quy định về chế độ, nội dung và thể thức của các báo cáo về môi trường. Mục đích của những quy định này là nhằm chuẩn hoá hoạt động báo cáo về môi trường của chính quyền địa phương, làm cho hoạt động này trở thành quy củ.

Thứ $b a$, xem trọng vai trò và tạo điều kiện cho tổ chức xã hội dân sự tham gia tích cực vào việc tương tác với chính quyền các cấp xuyên suốt quá trình chính sách ứng phó biến đổi khí hậu. Tổ chức dân sự môi trường đóng vai trò vừa là người tham gia vừa thổi còi báo động về môi trường. Đây còn là những tổ chức thể hiện rất tốt vai trò giám sát việc các vấn đề liên quan đến môi trường. Để có thể phát huy vai trò của nhóm đối tượng này, cần hướng tới một số việc làm dưới đây:

- Tăng cuờng tính phản biện của cộng đồng dân cu và xã hội dân sụ. Người dân Việt Nam có tư tưởng 'dựa dẫm, ỷ lại' và 'tư tưởng cầu an (an phận thủ thường) và cả nể. Làm gì cũng sợ bứt dây động rừng nên có việc gì là chủ trương đóng cửa bảo nhau' [12]. Đặc điểm tâm lý này góp phần lý giải vì sao số lượng các tổ chức xã hội dân sự không nhiều mặc dù nhà nước đã có những văn bản về việc khuyến khích hoạt động của các tổ chức xã hội dân sự: Nghị định 81/2002/NĐ-CP, Nghị định 88/2003/NĐ-CP, Nghị định Số 148/ND$\mathrm{CP} / 2007$. Đặc điểm tâm lý này cũng lý giải vì sao hoạt động của các tổ chức xã hội dân sự thường không có tính phản biện cao vì sợ 'đi ngược với nhà nước', nhất là những hoạt động liên quan đến kiện tụng và pháp luật.

Từ đặc điểm này, một trong những cách thức để thúc đẩy sự tham gia mạnh mẽ của người dân và tổ chức xã hội dân sự vào hoạt động bảo vệ môi trường là làm sao để nguò̀i dân và tố chức xã hội dân sự có thể kiện những tổ chức, cá nhân làm ô nhiếm, phá hoại môi trường, ảnh huớng trục tiếp đến quyền lọi của nguoòi dân. Đề làm được điều này, đòi hỏi phải có những điều kiện hết sức cơ bản. Trước hết là vai trò độc lập và mạnh mẽ của Hội Luật sư. Trong bối cảnh người dân ít am hiểu về luật pháp, và ít tin vào thành công của những vụ kiện tụng do đặc điểm tâm lý vừa nêu trên, tính chủ động, độc lập và quyết liệt của Hội Luật sư có thể nói là nơi để người dân tin tưởng gửi gắm tiếng nói và nguyện vọng của mình. Vụ Vedan là một minh chứng. Trong những trường hợp như vậy, các tổ chức dân sự trong đó có Hội Luật sư là điều mà người dân cần đến. Điều kiện thứ hai là tính trách nhiệm của chính quyền các cấp. Trong nhiều trường hợp, chính quyền các cấp giải quyết chậm trễ, hoặc không giải quyết những vấn đề ô nhiễm môi trường sau khi đã nhận được phản ánh của người dân, càng làm cho tình trạng ô nhiễm môi trường tăng lên. Điều này cho thấy, mức độ chịu trách nhiệm của cơ quan nhà nước thấp. Có người đặt vấn đề, trong trường hợp nhà nước chậm hoặc nhận được ý kiến phản hồi của người dân nhưng không bắt tay vào giải quyết, làm cho ô nhiễm trầm trọng thêm, liệu người dân có thể kiện cả nhà nước hay không? Những câu trả lời như vậy, cũng nên được Hội Luật sư xem xét và nghiên cứu giúp người dân tin tưởng hơn vào sự đấu tranh chính đáng của mình.

Các tổ chức phi chính phủ nước ngoài hoạt động trong linhh vưc môi trường cũng nên cân nhắc những đặc điểm về văn hoá của Việt Nam để từ đó thay đổi hướng hành động theo hướng có thể mang lại hiệu quả hơn. Thay vì tập trung vào những hoạt động tuyên truyền và nghiên cứu như hiện nay, cần có những biện pháp nâng cao sự tham gia của người dân và xã hội dân sự vào quá trình giảm thiểu ô nhiễm 
môi trường ở Thành phố Hồ Chí Minh nói riêng và cả nước nói chung.

Thứ tur, vấn đề cốt lõi của chính sách ứng phó biến đổi khí hậu, từ nghiên cứu ở Trung Quốc, không phải là nguồn lực, là cách thức phối hợp giữa chính quyền trung ương và chính quyền địa phương mà chính là ý thức và quan niệm của địa phương và trung ương về môi trường. Đó là tư duy và niềm tin về phát triển xanh vốn chưa thực sự được hành thành rõ nét ở các nước đang phát triển trong đó có Việt Nam do sự cám dỗ quá mạnh mẽ của tăng trưởng kinh trước mắt.

\section{Kết luận}

Chính quyền địa phương là chủ thể quan trọng trong quá trình thực hiện chính sách ứng phó biến đổi khí hậu; bởi chúng biến những ý niệm, mong muốn và kỳ vọng về chính sách của nhà nước thành kết quả thực tế. Với vai trò như vậy, chính quyền địa phương có thể làm cho quá trình thực hiện chính sách này trở nên thuận lợi hoặc khó khăn. Tác động đến chính quyền địa phương cần phải có một cái nhìn tổng thể, đồng bộ và đồng điệu với mong đợi của họ thì mới có thể làm cho cấp này trở thành một mắc xích hữu ích trong toàn bộ chu trình chính sách ứng phó biến đổi khí hậu.

\section{Tài liệu tham khảo}

[1] Chmutia, K., Zhu, J., Riffat, S. (2012), An analysis of climate change policy-making and implementation in China, International Journal of Climate Change Strategies and Management, Vol. 4, No.2, 2012, pp. 138-151

[2] Bjorkum, I. (2005), China in the International Politics of Climate Change: A Foreign Policy Analysis (FNI Report 12/2005), available at: www.fni.no/doc\&pdf/FNI-R1205.pdf (accessed 6 April 2008).

[3] Freestone, D. and Streck, C. (Eds) (2005), Legal Aspects of Implementing the Kyoto Protocol
Mechanism: Making Kyoto Work, Oxford University Press, Oxford.

[4] Heggelund, G. (2005), International CER Market and CD Experiences in Developing Countries (Final Report), CPR/01/002 and CPR/02/H02 Building Capacity for the CD in China, FNI.

[5] Fei Teng \& Alun Gu (2007) Climate change: national and local policy opportunities in China, Environmental Sciences, 4:3, 183-194, DOI: 10.1080/15693430701742735.

[6] Tsang, S. \& Kolk, A. (2010), The evolution of Chinese Policies and Governance Structures on Environment, Energy and Climate, Journal of Environmental Policy and Governance, Vol.20, pp.180-196

[7] Pressman J, Wildavsky A. (1984), How Great Expectations in Washington are Dashed in Oakland; Or, Why It's Amazing that Federal Programs Work at All, This Being a Saga of the Economic Administration as Told by Two Sympathetic Observers Who Seek to Build Morals on a Foun- dation of Ruined Hopes. University of California Press: Berkeley, CA

[8] Schreurs, M. (2017), Multi-level Climate Governance in China, Jouranl od Environmental Policy and Governance, Vol. 27, pp. 163-174. DOI: $10.1002 /$ eet.1751

[9] Kostka, G. (2014), Barriers to the implementation of Environmental Policies at the Local Level in China, Policy Research Working Paper 7016, World Bank Group, Development Research Group Environment and Energy Team, August 2014.

[10] Kostka, G. and Mol, A.P.J. (2013) Implementation and Participation in China's Local Environmental Politics: Challenges and Innovations, Journal of Environmental Policy \& Planning, 15 (1), 3-16.

[11] Gao, Ruge (2013). Rise of Environmental NGOs in China: Official Ambivalence and Contested Messages. Journal of Political Risk, Vol. 1, No. 8, December. Available at http://www.jpolrisk.com/rise-of-environmentalngos-in- china-official-ambivalence-andcontested-messages.

[12] Trần Ngọc Thêm (1999), Tìm về bản sắc văn hoá Việt Nam, NXB Văn Hoá, Hà Nội. 


\title{
Local Government and Climate Change Policy Implementation in China: Lessons for Vietnam
}

\author{
Ngo Hoai Son ${ }^{1}$, Nguyen Van $\mathrm{Hoa}^{2}$ \\ ${ }^{1}$ International University, Vietnam National University, HCM City, Quarter 6, \\ Linh Trung, Thu Duc, Ho Chi Minh City, Vietnam \\ ${ }^{2}$ Vietnam Institute of Science Technology and Innovation, Ministry of Science and Technology, \\ 38 Ngo Quyen, Hoan Kiem, Hanoi, Vietnam
}

\begin{abstract}
This paper applies desk research method with the use of available literature about China's Climate policy implementation at local government to review the vital role of local government in implementing this policy. The paper then analyses China's practices and draws four important lessons for Vietnam. Firstly, there is a need to combine top-down and bottom-up approaches in policy implementation. Secondly, the local government should focus on integrating the climate change response targets into its scio-economic development strategy and plans. Thirdly, it is necessary to raise the important roles of NGOs as well as generate favourable conditions for their effective interaction with local government during policy implementation. Fourthly, the awareness and perception of the local government about climate change is a crucial factor to ensure success of climate change policy implementation.
\end{abstract}

Keywords: Local government, climate change, China. 